\title{
Teenagers' oral health attitudes and behavior in Japan: comparison by sex and age group
}

\author{
Makoto Kawamura $^{1)}$, Naoko Takase ${ }^{2)}$, Hisako Sasahara ${ }^{1)}$ and Mitsugi Okada ${ }^{3)}$ \\ ${ }^{1)}$ Preventive Dentistry, Hiroshima University Hospital, Hiroshima, Japan \\ ${ }^{2}$ Research and Development Department, Sunstar Inc., Osaka, Japan \\ ${ }^{3}$ Special Care Dentistry, Hiroshima University Hospital, Hiroshima, Japan
}

(Received 24 October 2007 and accepted 1 April 2008)

\begin{abstract}
We investigated sex and age group differences in attitudes to oral health among school-age children using an Oral Self-Care Appraisal (OSCA) to systematically determine changes in oral health knowledge, attitude, and behavior across developmental stages. The subjects $(n=1584)$ were stratified after random sampling so that each school grade analyzed contained 88 boys and 88 girls. Factor analysis was undertaken to identify a set of underlying factors, with 10 factors considered in the cross-sectional study. Our results showed that the factors toothbrushing, persistence, and sociability were more predominant in primary school children than in junior high and senior high school students. Furthermore, postponement of visiting the dentist and resignation to one's own dental cavities became more predominant in proportion to the level of school education. Girls had significantly higher scores than boys for desire to improve oral care, dental anxiety, dependency on snacks, toothbrushing, concern over number of cavities, and sociability. Together, the results indicated that the oral health care behavior of girls was better than that of boys, and that the tendency to postpone visiting the dentist and resignation to one's own dental cavities increased markedly with age. (J. Oral Sci. 50, 167-174, 2008)
\end{abstract}

Keywords: oral health attitudes/behavior; developmental stages; sex differences; factor analysis.

Correspondence to Dr. Mitsugi Okada, Special Care Dentistry, Hiroshima University Hospital, 1-2-3 Kasumi, Minami-ku, Hiroshima 734-8553, Japan

Tel: +81-82-257-5788

Fax: +81-82-257-5789

E-mail: mitsugi@hiroshima-u.ac.jp

\section{Introduction}

Over the past two decades, there has been a dramatic decline in dental caries in 12-year-old children in a number of industrialized nations (1-3). However, prevention of dental caries is still an important issue worldwide. On the other hand, the prevalence of gingivitis, although considered preventable by thorough plaque control, remains very high during adolescence $(4,5)$.

For studying oral health behavior in children, it is necessary to use a questionnaire that systematically measures changes in oral health knowledge, attitudes, and behavior across developmental stages. Such information is helpful for understanding what should be taught and which behavioral changes are necessary for improvement of oral health, and also for developing strategies that could be used for educating children about good oral health habits.

Various epidemiologic studies of oral health behavior in children and adolescents have been reported from all parts of the world (6-9), and generally they have indicated that oral health behavior in girls is better than that in boys. However, oral health behavior in schoolchildren has not been fully understood, and data on aspects such as oral condition (tooth decay) and oral hygiene habits (toothbrushing and flossing) are limited. In addition, there have been few attempts to assess the general concept of oral health behavior in primary, junior high, and high school children. Moreover, although a number of studies have investigated the oral health behavior of adolescents (10-12), little is known about factors responsible for changes in oral health behavior during the development of young people.

Kawamura et al. (13) previously developed a questionnaire regarding oral self-care for junior high and senior 
high school students. The test-retest reliabilities for the items in the survey were found to range from 0.40 to 0.79 (1 month apart), which is considered suitable at the clinical level. They interviewed primary school children to determine whether the subjects could understand oral selfcare in order to develop a questionnaire that could be broadly modified for children in each developmental stage (from primary school to senior high school). After some minor changes and deletions, the Oral Self-Care Appraisal (OSCA) questionnaire containing 30 items was developed. In the present study, we investigated sex and age group differences in oral health behavior of school-aged children using the OSCA.

\section{Subjects}

\section{Subjects and Methods}

In collaboration with the public dental health committee of the Kamo/Higashi-Hiroshima Dental Association, four schools in and around Higashi-Hiroshima City were randomly selected, including a primary school (School A), junior high school (School B), and senior high school (School C), each located within the city, as well as another senior high school (School D) located in a nearby rural district. The principals of the schools were contacted about the proposed investigation and all agreed to administer the questionnaire to their students one week prior to an oral health check-up.

We administered the OSCA, comprising 30 items, to students in primary School A (Grades 4-6; 10 to 12 years of age), junior high School B (Grades 7-9; 13 to 15 years of age), and senior high School C and D (Grades 10-12; 16 to 18 years of age). The distribution of the study population by sex and grade is shown in Table 1 . Questionnaire recovery rates were $97.3 \%$ (614 of 631) for those administered at School A, 92.5\% (558 of 603) for those at School B, 96.7\% (1274 of 1318) for those at School C, and 94.2\% (425 of 451) for those at School D. The total recovery rate was $95.6 \%$ (2871 of 3003).

Previous reports have indicated that, in general, schoolaged girls have better oral health behavior than school-aged boys (14-16). In order to reduce the influence of extracted factors that may cause differences in boy/girl ratios, the ratio of boys to girls must be 1:1 for every grade level examined. Appropriate subjects were randomly selected to adjust the sex ratio to $1: 1$ by computer, neglecting subjects who incompletely answered the questionnaires. Since the sex ratio was $1: 1$, the 10 factors extracted were considered to have a certain degree of universality in our analyses. Furthermore, in order to utilize standard criteria according to developmental stage, the candidates were stratified by random sampling so that every school grade consisted of 88 boys and 88 girls. For the two senior high schools, 44 students for each sex and grade were selected at random from each. As a result, 1584 subjects with an equal distribution by sex and grade group were selected for analysis.

Table 1 Number of subjects by school and gender

\begin{tabular}{lcccc}
\hline Cross Table & Year & Boys & Girls & Total \\
\hline Primary School A & 4 & $88(97)$ & $88(104)$ & $176(201)$ \\
$614 / 631=0.973^{*}$ & 5 & $88(96)$ & $88(100)$ & $176(196)$ \\
& 6 & $88(95)$ & $88(122)$ & $176(217)$ \\
A total & & $264(288)$ & $264(326)$ & $528(614)$ \\
\hline Junior high school B & 7 & $88(88)$ & $88(99)$ & $176(187)$ \\
$558 / 603=0.925^{*}$ & 8 & $88(93)$ & $88(92)$ & $176(185)$ \\
& 9 & $88(88)$ & $88(98)$ & $176(186)$ \\
B total & & $264(269)$ & $264(289)$ & $528(558)$ \\
\hline Senior high school C & 10 & $44(181)$ & $44(244)$ & $88(425)$ \\
$1274 / 1318=0.967^{*}$ & 11 & $44(181)$ & $44(244)$ & $88(425)$ \\
& 12 & $44(162)$ & $44(262)$ & $88(424)$ \\
C total & & $132(524)$ & $132(750)$ & $264(1274)$ \\
\hline Total & 10 & $44(80)$ & $44(71)$ & $88(151)$ \\
\hline Senior high school D & 11 & $44(53)$ & $44(83)$ & $88(136)$ \\
$425 / 451=0.942^{*}$ & 12 & $44(67)$ & $44(71)$ & $88(138)$ \\
& & $132(200)$ & $132(225)$ & $264(425)$ \\
& & $792(1281)$ & $792(1590)$ & $1584(2871)$ \\
\hline
\end{tabular}

Recovery number is shown in brackets. * Recovery rate. 


\section{Statistical analyses}

Principal component factor analysis was undertaken to identify the set of underlying factors contributing to the OSCA responses, with the answers rated as follows: agree $=4$, somewhat agree $=3$, somewhat disagree $=2$, and disagree $=1$. This was followed by a promax rotation of the factors that accounted for the greatest amount of variation and computation of factor loadings for each question to identify any that exceeded 0.45 (SPSS Inc, 1999), which was used as a threshold for moderate to high loadings. An item was assigned to factor $\mathrm{X}$ when its absolute value of loading was more than 0.45 and it had no loading at 0.35 or higher for another factor. Differences among school levels (primary, junior high, and senior high) for each factor score were evaluated using analysis of variance, and differences between boys and girls were evaluated using independent $t$-tests.

\section{Results}

Table 2 shows the answers by percentage for the 10 factors extracted by promax rotation. Items with a loading below 0.45 were not reported. Ten socio-psychological factors labeled desire to improve oral care (f1), dental anxiety (f2), dependency on snacks (f3), toothbrushing (f4),

Table 2 Answers to 10 factors extracted by promax rotation

\begin{tabular}{|c|c|c|c|c|c|}
\hline Item descriptions & Agree $(\%)$ & $\begin{array}{l}\text { Somewhat } \\
\text { Agree (\%) }\end{array}$ & $\begin{array}{l}\text { Somewhat } \\
\text { Disagree }(\%)\end{array}$ & Disagree $(\%)$ & $\begin{array}{l}\text { Factor* } \\
\text { loading }\end{array}$ \\
\hline \multicolumn{6}{|l|}{ f1. Desire to improve oral care (DIOC) } \\
\hline 12. I would like to learn how best to brush my teeth. & 17 & 23 & 30 & 30 & 0.69 \\
\hline 18. I feel the condition of my teeth plays an important role in daily life. & 23 & 30 & 26 & 22 & 0.51 \\
\hline 22. I want to know how to use dental floss properly. & 11 & 15 & 28 & 46 & 0.69 \\
\hline 24. I would like to use chewing gum or mouth spray to improve my breath. & 19 & 27 & 25 & 29 & 0.51 \\
\hline 28. I want to know my chances of getting cavities. & 33 & 28 & 19 & 20 & 0.72 \\
\hline 30. I feel that it is fashionable to have beautiful teeth. & 27 & 33 & 21 & 19 & 0.56 \\
\hline \multicolumn{6}{|l|}{ f2. Dental anxiety (DA) } \\
\hline 15. I get nervous the day before visiting the dentist. & 10 & 12 & 18 & 60 & 0.89 \\
\hline 21. I worry about what my treatment will be like in the waiting room. & 19 & 22 & 19 & 40 & 0.87 \\
\hline 27.I feel uncomfortable when I receive my oral health checkup at school. & 18 & 26 & 22 & 35 & 0.61 \\
\hline \multicolumn{6}{|l|}{ f3. Dependency on snacks (DOS) } \\
\hline 14. I often eat too many snacks to the point where I am unable to eat meals. & 11 & 21 & 21 & 46 & 0.66 \\
\hline 20. I tend to eat snacks in my free time. & 15 & 24 & 30 & 31 & 0.80 \\
\hline 26. I have many opportunities to eat snacks at home or outside. & 16 & 28 & 33 & 23 & 0.83 \\
\hline \multicolumn{6}{|l|}{ f4. Toothbrushing (TB) } \\
\hline 4. I often check my teeth in a mirror after brushing. & 33 & 27 & 19 & 21 & 0.70 \\
\hline 9. I brush each of my teeth carefully. & 16 & 33 & 36 & 15 & 0.73 \\
\hline 11. I have had my dentist tell me that I brush very well. & 7 & 9 & 22 & 63 & 0.66 \\
\hline \multicolumn{6}{|l|}{ f5. Persistence (Persist) } \\
\hline 17. Often when I start something I never finish it. & 14 & 29 & 37 & 20 & -0.82 \\
\hline 23. I try to be persistent in what $\mathbf{I}$ do. & 21 & 44 & 27 & 8 & 0.49 \\
\hline 29. I continue doing things, even when they are difficult. & 14 & 33 & 37 & 16 & 0.77 \\
\hline \multicolumn{6}{|l|}{ f6. Concern over number of cavities (CONC) } \\
\hline 1. I had many cavities when I was young. & 13 & 30 & 29 & 28 & 0.76 \\
\hline 6. I develop new cavities soon after being treating by the dentist. & 7 & 16 & 29 & 48 & 0.77 \\
\hline \multicolumn{6}{|l|}{ f7. Expectation of fluoride's effect (EFE) } \\
\hline 3. I think fluoride paste is good for the gums. & 11 & 31 & 33 & 25 & 0.84 \\
\hline 8. I think fluoride treatments prevent cavities. & 19 & 33 & 30 & 19 & 0.86 \\
\hline \multicolumn{6}{|l|}{ f8. Sociability (Soc) } \\
\hline 5. I feel 1 am a happy person. & 36 & 36 & 20 & 8 & 0.78 \\
\hline 10. I usually try to respond to a smile with a smile. & 42 & 40 & 13 & 5 & 0.77 \\
\hline \multicolumn{6}{|l|}{ f9. Postponement of visiting the dentist (PVD) } \\
\hline 2. I put off going to the dentist until I have a toothache. & 22 & 25 & 21 & 32 & 0.64 \\
\hline 7. I go to the dentist when the school dentist finds a cavity in my mouth. & 41 & 26 & 21 & 12 & -0.69 \\
\hline \multicolumn{6}{|l|}{ f10. Resignation to own cavities (RTOC) } \\
\hline 13. It is possible to treat a cavity at its early stage by brushing. & 19 & 23 & 27 & 31 & 0.48 \\
\hline 19. I feel cavities are impossible to avoid. & 10 & 16 & 28 & 46 & 0.77 \\
\hline 25. Some people have teeth that decay easily. & 11 & 13 & 28 & 48 & 0.73 \\
\hline
\end{tabular}


Table 3 Comparison of scores of 10 factors by gender

f1: Desire to improve oral care
f2: Dental anxiety
f3: Dependency on snacks
f4: Toothbrushing
f5: Persistence
f6: Concern over number of cavities
f7: Expectation of fluoride's effect

Independent $t$-test, $*: P<0.05, * *: P<0.01, * * *: P<0.001$

persistence (f5), concern over number of cavities (f6), expectation of effect of fluoride (f7), sociability (f8), postponement of visiting the dentist (f9), and resignation to one's own dental cavities (f10) were extracted.

Table 3 shows a comparison of the scores for $\mathrm{f} 1-10$ by gender. There were significant differences between the sexes for 8 factors, excluding expectation of the effect of fluoride and resignation to one's own dental cavities. The scores for desire to improve oral care, dental anxiety, dependency on snacks, toothbrushing, and sociability were higher for girls than for boys $(P<0.001)$, whereas those for persistence and postponement of visiting the dentist were higher for boys $(P<0.05, P<0.001$, respectively).

Table 4 shows a comparison of the scores for the 10 factors by grade level in boys. Toothbrushing, persistence, and sociability had higher scores for primary school boys than for boys in junior high and senior high schools $(P<$ $0.001)$. Furthermore, postponement of visiting the dentist and resignation to one's own dental cavities became more predominant as the level of school education increased $(P$ $<0.001)$. In contrast, there were no significant differences in scores for desire to improve oral care, dental anxiety, dependency on snacks, concern over number of cavities, or expectation of the effect of fluoride among the three levels of education.

Table 5 shows a comparison of the scores for the 10 factors by grade level in girls. Toothbrushing and persistence had higher scores in primary school girls as compared to girls in junior high and senior high schools $(P<0.001)$. Furthermore, the score for sociability for primary school girls was more predominant than for girls in junior high and senior high schools (primary school vs junior high school girls, $P<0.001$; primary school vs senior high school girls, $P<0.05)$. In contrast, dependency on snacks, postponement of visiting the dentist, and resignation to one's own dental cavities were less prominent in primary school girls $(P<0.001)$. In addition, the score for concern over numbers of cavities was significantly higher for senior high school girls than for girls in junior high school $(P<0.05)$. There were no significant differences in scores for desire to improve oral care, dental anxiety, and expectation of the effect of fluoride among the three levels of education.

\section{Discussion}

In the present study, the obtained data were factor analyzed using promax rotation that provided an oblique solution, as opposed to varimax rotation that gives a rectangular solution. Varimax rotation is often used to obtain factors without mutual correlation, whereas oblique rotation offers solutions that recognize the relevance between mutual factors. As it is generally accepted that naturally occurring phenomena are never totally unrelated, 
Table 4 Comparison of 10 factors by grade level for boys

\begin{tabular}{|c|c|c|c|}
\hline & Grades 4-6 & Grades 7-9 & Grades 10-12 \\
\hline fl: Desire to improve oral care & -0.176 & -0.199 & -0.001 \\
\hline f2: Dental anxiety & -0.193 & -0.149 & -0.068 \\
\hline f3: Dependency on snacks & -0.144 & -0.185 & -0.118 \\
\hline \multirow[t]{2}{*}{ f4: Toothbrushing } & 0.065 & -0.263 & -0.242 \\
\hline & \multicolumn{3}{|c|}{ 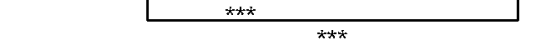 } \\
\hline \multirow[t]{2}{*}{ f5: Persistence } & 0.412 & $-0,122$ & -0.140 \\
\hline & \multicolumn{3}{|c|}{$* * * *$} \\
\hline f6: Concern over number of cavities & 0.005 & -0.163 & -0.044 \\
\hline f7: Expectation of fluoride's effect & -0.052 & -0.071 & -0.014 \\
\hline \multirow[t]{3}{*}{ f8: Sociability } & 0.064 & $-0,444$ & \multirow[t]{2}{*}{-0.258} \\
\hline & & 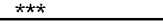 & \\
\hline & & 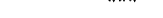 & \\
\hline \multirow[t]{2}{*}{ f9: Postponement of visiting the dentist } & $-0,365$ & 0.198 & \multirow[t]{2}{*}{0.417} \\
\hline & & 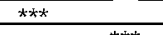 & \\
\hline \multirow[t]{2}{*}{ f10: Resignation to own cavities } & $-0,241$ & -0.047 & \multirow[t]{2}{*}{$0.1^{12}$} \\
\hline & & & \\
\hline
\end{tabular}

Independent $t$-test, ${ }^{*}: P<0.05,{ }^{* *}: P<0.01,{ }^{* * *}: P<0.001$

Table 5 Comparison of 10 factors by grade level for girls

\begin{tabular}{|c|c|c|c|}
\hline & Grades 4-6 & Grades 7-9 & Grades $10-12$ \\
\hline $\mathrm{fl}$ : Desire to improve oral care & 0.157 & 0.136 & 0.083 \\
\hline f2: Dental anxiety & 0.062 & 0.127 & 0.222 \\
\hline \multirow[t]{3}{*}{ f3: Dependency on snacks } & -0.190 & 0.336 & \multirow[t]{2}{*}{0.301} \\
\hline & \multicolumn{2}{|c|}{$* ;-k$} & \\
\hline & & *** & \multirow{3}{*}{-0.066} \\
\hline \multirow[t]{2}{*}{ f4: Toothbrushing } & 0.536 & -0.031 & \\
\hline & & $* * *$ & \\
\hline \multirow[t]{2}{*}{ f5: Persistence } & 0.285 & -0.277 & \multirow[t]{2}{*}{-0.159} \\
\hline & & $* * * k$ & \\
\hline \multirow[t]{2}{*}{ f6: Concern over number of cavities } & 0.128 & -0.073 & 0.147 \\
\hline & & \multicolumn{2}{|c|}{ * } \\
\hline f7: Expectation of fluoride's effect & 0.132 & -0.063 & -0.035 \\
\hline \multirow[t]{3}{*}{ f8: Sociability } & 0.391 & 0.039 & \multirow[t]{3}{*}{0.208} \\
\hline & & 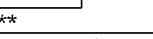 & \\
\hline & & * & \\
\hline \multirow[t]{3}{*}{ f9: Postponement of visiting the dentist } & -0.498 & 0.009 & \multirow{2}{*}{0.238} \\
\hline & & ** & \\
\hline & & $* * *$ & \\
\hline \multirow[t]{2}{*}{ f10: Resignation to own cavities } & -0.377 & -0.043 & \multirow[t]{2}{*}{0.436} \\
\hline & & $\pi *$ & \\
\hline
\end{tabular}

Independent $t$-test, ${ }^{*}: P<0.05,{ }^{* *}: P<0.01,{ }^{* * *}: P<0.001$ 
oblique rotation has been suggested to produce results that are more practical (17).

In the present study, school-aged girls had higher scores for dental anxiety than boys, but there were no significant differences with regard to school grade for both sexes. Neverlien (18) found that the levels of self-reported dental anxiety in a Norwegian adult population varied with gender and age. In another study, it was reported that women and younger subjects had higher levels of dental anxiety than men and older subjects, though the age of those subjects was higher than in the present study (19). Since there is scant information regarding oral health behavior in later adolescence, it is still unknown whether dental anxiety decreases with age. Wright (14) reported that the proportion of subjects with low dental anxiety decreased from $39.6 \%$ for 6- to 8 -year-old subjects to $18.0 \%$ for those 11 to 13 years old, and then to $15.2 \%$ for 14 - to 16-year-old subjects. From those results, it was suggested that the difference in dental anxiety with age was consistent with two maturational phenomena; an increased likelihood of unpleasant dental experiences resulting from direct personal experiences with increasing age, and changes in the cognitive ability of children as they age, as adolescents have an increasing ability to rationalize experiences and abstract their feelings. In the present study, even in older adolescents with a higher maturation level, the level of dental anxiety tended to increase in both boys and girls, although there were no significant differences among the three levels of education. Thus, our results also indicate that unpleasant dental experiences increase with age.

In both sexes, there was a remarkable age-related increase in scores for postponement of visiting the dentist, which was in agreement with the tendency for the increases in scores for dental anxiety and resignation to one's own dental cavities. One reason may be the control maintained by the public health dental services in Japan, which includes annual dental examinations held during school time at schools, as this might tend to restrict the development of an individual's sense of responsibility in students. Entrance to junior high school generally marks the beginning of critical developmental and transitional stages. During this period of transition into adolescence, many children develop fatalistic beliefs regarding oral diseases, along with a decrease in their individual sense of value, self-esteem, and sociability, which occurs with increasing age. The traits seen in our study are in agreement with an earlier report that utilized cluster analysis (20). Furthermore, comparisons of data from studies of western populations in the UK, Australia, Ireland, and elsewhere indicate that a higher percentage of people living in Asia put off going to the dentist until they have toothache (western, $12 \%$ vs Asia,
$47 \%$ ), and only a small proportion (8\%) of the western subjects reported a perception of inevitability in having false teeth, whereas 33\% of Asians studied held this fatalistic belief.

Pre-adolescents have been shown to brush their own teeth more often than adolescents in Japan (21). In general, dental care from the guardian (mainly mother) seems to heavily influence the toothbrushing habits of infants and primary school children (22). Fitzgerald et al. (23) reported that preferred oral health behavior associated with a medicalized model among adolescents was frequent use of chewing gum and rapid toothbrushing, while for the cosmetic model frequent use of chewing gum and breath fresheners was noted. In the present study, high school students, especially girls, tended to depend more on snacks (sweets) than pre-adolescent subjects. Cutress (24) reported that knowledge of the effects of sugar intake and use of fluoride is a predictor of prevalence for public health purposes, and that no other proven inhibitors of caries through diet are available. Caries risk is primarily caused by supplementation of diet with pure sugars, which initiate the caries process by intra-oral metabolism. Dental caries becomes a significant public health problem in populations that have per capita annual consumption of sugars that exceeds $20 \mathrm{~kg}$, while fluoride as a component of the diet or when applied by other intra-oral routes exerts a significant anti-caries effect despite the availability of sugars (24).

Nakazono et al. (25) reported that four items, fluoridated water to prevent caries, fluoride supplementation to stop decay, toothbrushing and fluorinated water to stop caries, and brushing to solve gum problems, were highly beneficial preventive practices. Fluoride intake during meals or application of fluoride in the oral cavity through other means is effective against caries, irrespective of whether or not sugar is consumed. In the present study, the expectation of the effect of fluoride (f7) by the subjects involved two items: "I think fluoride treatments prevent cavities" and "I think fluoride paste is good for the gums". The results showed that expectation of the effect of fluoride was not related to knowledge about fluoride, but rather some mere expectation of its effect by the subjects. Grembowski et al. (26) have suggested that fluoride has very little effect on the gums. The respondents in this study were students in their fourth to twelfth year of public school, and the purpose of their education was to prepare them for a variety of situations, including common problems encountered in everyday life. Although research has provided a lot of information on the cause and effects of dental caries and periodontal disease, the present teenagers knew little about those issues and were doing relatively little to prevent oral health problems. 
By utilizing the 10 factors of the OSCA, a better understanding of the psychosocial influences on oral health could assist efforts by schools and the community to maintain and promote lifelong healthy oral conditions. If the oral health behavior of school-aged children could be measured, intervention strategies for behavioral change used by the schools could be planned. Furthermore, it would also be possible to compare the results with the attitudes and behavior of the parents, which would provide verification of whether parents are influential role models for their children with regard to oral health behavior. In addition, a simultaneous interrelationship of oral health behavior (10 factors in the present study) and the oral health of children could be examined using linear structural relations (LISREL) analysis in the next stage.

In the present cross-sectional study, 10 scales in the OSCA were used to assess determinants of oral health attitudes and behavior of school-aged children. Factor analysis provided interpretable scales that could be used as variables. Since all of the subjects were recruited from public schools in the general area of the same city, further research is needed to determine whether similar results could be obtained from other areas and/or foreign countries, where culture, race, and/or health insurance systems differ. Nevertheless, we consider that information acquired by use of the OSCA is useful for understanding changes in oral health behavior during the development of children.

\section{Acknowledgments}

The authors express their thanks to Dr. Hiromichi Tomita for helping to coordinate this project in Higashi-Hiroshima City and Mr. Kurt Pipa, in association with Sunstar Inc., for his assistance in translating the manuscript into English.

\section{References}

1. Blinkhorn AS, Davies RM (1996) Caries prevention. A continued need worldwide. Int Dent J 46, 119125

2. Miyazaki H, Morimoto M (1996) Changes in caries prevalence in Japan. Eur J Oral Sci 104, 452-458

3. Downer MC (1998) The changing pattern of dental disease over 50 years. Br Dent J 185, 36-41

4. Glickman I (1972) Clinical periodontology. 4th ed, WB Saunders, Philadelphia, 441-478

5. Albander JM, Rams TE (2002) Global epidemiology of periodontal diseases: an overview. Periodontol $200029,7-10$

6. Kuusela S, Honkala E, Rimpelä A (1996) Toothbrushing frequency between the ages of 12 and 18 years - longitudinal prospective studies of Finnish adolescents. Community Dent Health 13, 34-39
7. Kuusela S, Honkala E, Kannas L, Tynjälä J, Wold B (1997) Oral hygiene habits of 11-year-old schoolchildren in 22 European countries and Canada in 1993/1994. J Dent Res 76, 1602-1609

8. Poutanen R, Lahti S, Hausen H (2005) Oral healthrelated knowledge, attitudes, and beliefs among 11 to 12-year-old Finnish schoolchildren with different oral health behaviors. Acta Odontol Scand 63, 1016

9. Poutanen R, Lahti S, Tolvanen M, Hausen H (2007) Gender differences in child-related and parentrelated determinants of oral health-related lifestyle among 11- to 12-year-old Finnish schoolchildren. Acta Odontol Scand 65, 194-200

10. Honkala E (1995) Oral health promotion with children and adolescents. In Disease prevention and oral health promotion, Cohen LK, Gift HC eds, Munksgaard, Copenhagen, 169-187

11. Koivusilta L, Honkala S, Honkala E, Rimpelä A (2003) Toothbrushing as part of the adolescent lifestyle predicts education level. J Dent Res 82, 361366

12. Dumitrescu AL, Kawamura M, Dogaru B, Dogaru C (2008) Investigating the relationship between self-reported oral health status, oral health-related behaviors and self-consciousness in Romania. Oral Health Prev Dent (in press)

13. Kawamura M, Okada M, Sasahara H (2005) Development of an oral self-care appraisal (OSCA) questionnaire for youth and test-retest reliability of its items. Hiroshima Daigaku Shigaku Zasshi 37, 7281 (in Japanese)

14. Wright FAC (1984) An assessment of dental health education. N Z Dent J 80, 74-80

15. ter Horst G, de Wit CA (1993) Review of behavioural research in dentistry 1987-1992: dental anxiety, dentist-patient relationship, compliance and dental attendance. Int Dent J 43, Suppl 1, 265-278

16. Åstrøm AN, Jakobsen R (1998) Stability of dental health behavior: a 3-year prospective cohort study of 15-, 16- and 18-year-old Norwegian adolescents. Community Dent Oral Epidemiol 26, 129-138

17. SPSS (1999) SPSS Base 10.0 Applications Guide. SPSS, Chicago, 317-358

18. Neverlien PO (1990) Normative data for Corah's Dental Anxiety Scale (DAS) for the Norwegian adult population. Community Dent Oral Epidemiol 18,162

19. Syrjälä AM, Knuuttila ML, Syrjälä LK (1990) Suitability of Krathwohl's affective taxonomy for evaluating patient attitudes to dental care. 
Community Dent Oral Epidemiol 18, 299-303

20. Kawamura M, Wright FA, Declerck D, Freire MC, Hu DY, Honkala E, Levy G, Kalwitzki M, Polychronopoulou A, Yip HK, Kinirons MJ, Eli I, Petti S, Komabayashi T, Kim KJ, Razak AA, Srisilapanan P, Kwan SY (2005) An exploratory study on cultural variations in oral health attitudes, behaviour and values of freshman (first-year) dental students. Int Dent J 55, 205-211

21. Uematsu M, Furuya M, Usui S, Kawamura K, Nakajima E, Arakawa H (2003) A survey on the use of fluoride dentifrice among kindergarten children and their guardians, primary school children and their guardians, and junior high school students in 2000. Koku Eisei Gakkai Zasshi 53, 111-120 (in Japanese)

22. Okada M, Kawamura M, Kaihara Y, Matsuzaki Y, Kuwahara S, Ishidori H, Miura K (2002) Influence of parents' oral health behaviour on oral health status of their school children: an exploratory study employing a causal modelling technique. Int $\mathbf{J}$ Paediat Dent 12, 101-108

23. Fitzgerald RP, Thomson WM, Schafer CT, Loose MA (2004) An exploratory qualitative study of Otago adolescents' views of oral health and oral health care. NZ Dent J 100(3), 62-71

24. Cutress TW (1996) Nutrition and dental caries in Pacific RIM countries. Int Dent J 46, Suppl 1, 388392

25. Nakazono TT, Davidson PL, Andersen RM (1997) Oral health beliefs in diverse populations. Adv Dent Res 11, 235-244

26. Grembowski D, Fiset L, Spadafora A Milgrom P (1993) Fluoridation effects on periodontal disease among adults. J Periodont Res 28, 166-172 